A - Research concept and design

B - Collection and/or assembly of data

$\mathrm{C}$ - Data analysis and interpretation

D - Writing the article

E - Critical revision of the article

F - Final approval of article

Received: 2021-04-13

Accepted: 2021-07-10

Published: 2021-07-13

\section{The effectiveness of neural mobilization in addition to conservative physiotherapy on cervical posture, pain and functionality in patients with cervical disc herniation}

\author{
Tecelli Kayiran ${ }^{1, A-B, D-F}$ (D), Begumhan Turhan*2,C-F (D) \\ ${ }^{1}$ Kahramanmaras Turkoglu Dr. Kemal Beyazit Hospital, Kahramanmaras, \\ Turkey \\ ${ }^{2}$ Hasan Kalyoncu University, Faculty of Health Sciences, Department of \\ Physiotherapy and Rehabilitation, Turkey
}

*Correspondence: Begumhan Turhan; Hasan Kalyoncu University, Faculty of Health Sciences, Department of Physiotherapy and Rehabilitation, Turkey; begum. aliosmanoglu@hku.edu.tr

\title{
Abstract
}

Introduction: Medical treatment, conservative physiotherapy (CP), exercise, mobilization and prevention methods should be taken into consideration in cervical problems. We aimed to investigate the efficacy of neural mobilization (NM) combined with $\mathrm{CP}$ on cervical posture, pain functionality in patients with cervical disc herniation $(\mathrm{CDH})$.

Material and methods: Sixty patients with $\mathrm{CDH}$ and radicular pain participated in this randomized controlled study. They were randomly allocated into two groups. The control group $(n=30)$ received CP (hotpack, transcutaneous electrical nerve stimulation, ultrasound), and the experimental group $(\mathrm{n}=30)$ received CP plus NM on the radial, median and ulnar nerves. Both groups received the $\mathrm{CP}$ for three weeks ( 15 sessions). The experimental group received the neural mobilization technique for three weeks (3 sessions per week). The demographic data, severity of pain (by Visual Analog Scale), cervical active range of motion degree, and cervical posture data (by Tragus to Wall test, Measurement of C7 to Wall Distance) have been recorded. Neck Disability Index (NDI) was applied to all participants for functionality.

Results: The distance between tragus and the wall decreased in the experimental group $(p<0.05)$, whereas there was not any significant difference in the distance between $C 7$ and the wall $(p>0.05)$. The scores of pain and cervical active range of motion were found different in favor of the experimental group $(p<0.05)$. The NDI scores were similar in both groups $(\mathrm{p}>0.05)$.

Conclusion: CP together with NM techniques will provide additional gains in cervical posture, pain, and active range of motion in patients diagnosed with cervical disc herniation.

Keywords: nerve stretching, radiculopathy, rehabilitation

\section{Introduction}

Cervical disc herniation $(\mathrm{CDH})$ is the clinical situation which is caused by the displacement of the intervertebral disc or nucleus pulposus towards the cervical spinal canal. Cervical disc herniation occurs especially after the age of forty with disc degeneration, and the deterioration of the natural structure of bones and joints $[1,2]$. Neck pain is the most common symptom of CDH. Often radiculopathy, with pain radiating to the arm, paresthesia, sensory, motor and reflex changes, is observed [3]. 
Intervertebral disc pathologies of the cervical region are the second most common of all intervertebral disc diseases after lumbar vertebral disc diseases. Although they can be seen in young adults, their incidence increases in the 45-50 age group, and they are also more common in females [4]. Medical treatment, conservative physiotherapy, exercise therapy, mobilization methods and prevention methods should be taken into consideration in cervical region problems, and the treatment approach to address the problem should be applied using a wide perspective [5]. Neural mobilization, which began to gain popularity in the recent years, consist of movements called neural glides. These techniques gently stretch and mobilize the nerves and surrounding structures. Neural mobilization is believed to ameliorate symptoms by promoting intraneural circulation, axoplasmic flow, and neural viscoelasticity and sensitivity associated with the connective tissue. There are studies in which these techniques have yielded therapeutic success in terms of pain and functionality, particularly in the cervical region and in upper limb disorders where neural mechanosensitivity is increased [6-8].

Neural mobilization is one of the methods used for manual treatment of the peripheral nervous system and tissues surrounding it. Neural mobilization techniques and their underlying mechanisms have been the subject of numerous clinical studies, especially in recent years. Neural mobilization contributes to restoring the ability of neural tissues to stretch, allowing for the restimulation of normal physiological function of neural structures [9]. The main goal of neural mobilization is to increase optimal neurophysiological function and reduce extrinsic pressures on nerve tissue by restoring the dynamic balance between the mechanical interfaces surrounding the nerve tissue and the movement thereof [10].

In a study, which neural mobilization and conservative physiotherapy were compared in patients with chronic mechanical neck pain, symptoms such as pain and numbness were significantly reduced in the neural mobilization treatment group when compared to the conservative physiotherapy group [11]. Pain inhibition may be accompanied by postural improvements $[12,13]$. The studies, which examining the effects of neural mobilization tecniques in addition to conservative treatment, observed more significant improvement in functionality scores was observed in the neural mobilization group $[14,15]$. The aim of this randomized study was to compare the effects of the routine conservative physiotherapy with and without neural mobilization techniques on cervical posture, pain and functionality in patients diagnosed with cervical disc herniation.

\section{Materials and methods}

\section{Participants}

A total of 88 patients were diagnosed by a physician and evaluated in the hospital. The criteria for subject inclusion were the following: Cervical disc herniation at the level of bulging or protrusion (C5-C6-C7-C8) based on clinical presentation and confirmed by magnetic resonance imaging (MRI), age between 20-50 years, cervicobrachial radicular pain for at least six weeks, pain severity at a minimum of level 5 according to the Visual Analog Scale (VAS), sensitivity and numbness in radial, median, ulnar nerve neurodynamic tests, not receiving any other treatment or pharmacological agents. Surgery was not recommended to the participants by the neurosurgeon. Patients with spinal stenosis, rheumatic diseases, previous cervical spine surgery history, severe neurological loss, upper extremity vascular problems, severe osteoporosis, diabetes mellitus and pregnant women were excluded from the study. A total of 71 patients who met the inclusion criteria participated in the study. Patients were randomized into two groups according to their hospital protocol numbers (Study group: 36 patients, Control group: 35 patients) (Fig. 1). The study was conducted between August 2019 and April 2020. Informed consent was obtained from all individuals included in this study.

\section{Ethical approval}

The ethical approval was obtained from the ethical committee of Hasan Kalyoncu University (ethics committee decision No: 2019-63, date of approval: 14.06.2019).

\section{Measurements}

The demographic information of individuals was recorded. The patients were asked to adopt a painless posture at the hip level while facing straight ahead, feet apart and heels against the wall Tragus-wall distance $(\mathrm{cm})$ and $\mathrm{C} 7$-wall distance $(\mathrm{cm})$ were measured [16]. Pain severity of patients was measured on a visual ana$\log$ scale (VAS), which is a high reliable as well as valid method to assess the severity of pain [17]. The universal goniometer was used to measure the active neck flexion, extension and right and left lateral flexion. The measurements were taken in a sitting position [18]. The Neck Disability Index (NDI) was used to determine the functionality level of the patients [19]. All patients were evaluated blind pre- and post-treatment. The physiotherapists who made the initial assessment and the final assessment were different.

\section{Treatment protocol}

A routine conservative physiotherapy protocol applied to the patients in the control group for 3 weeks 


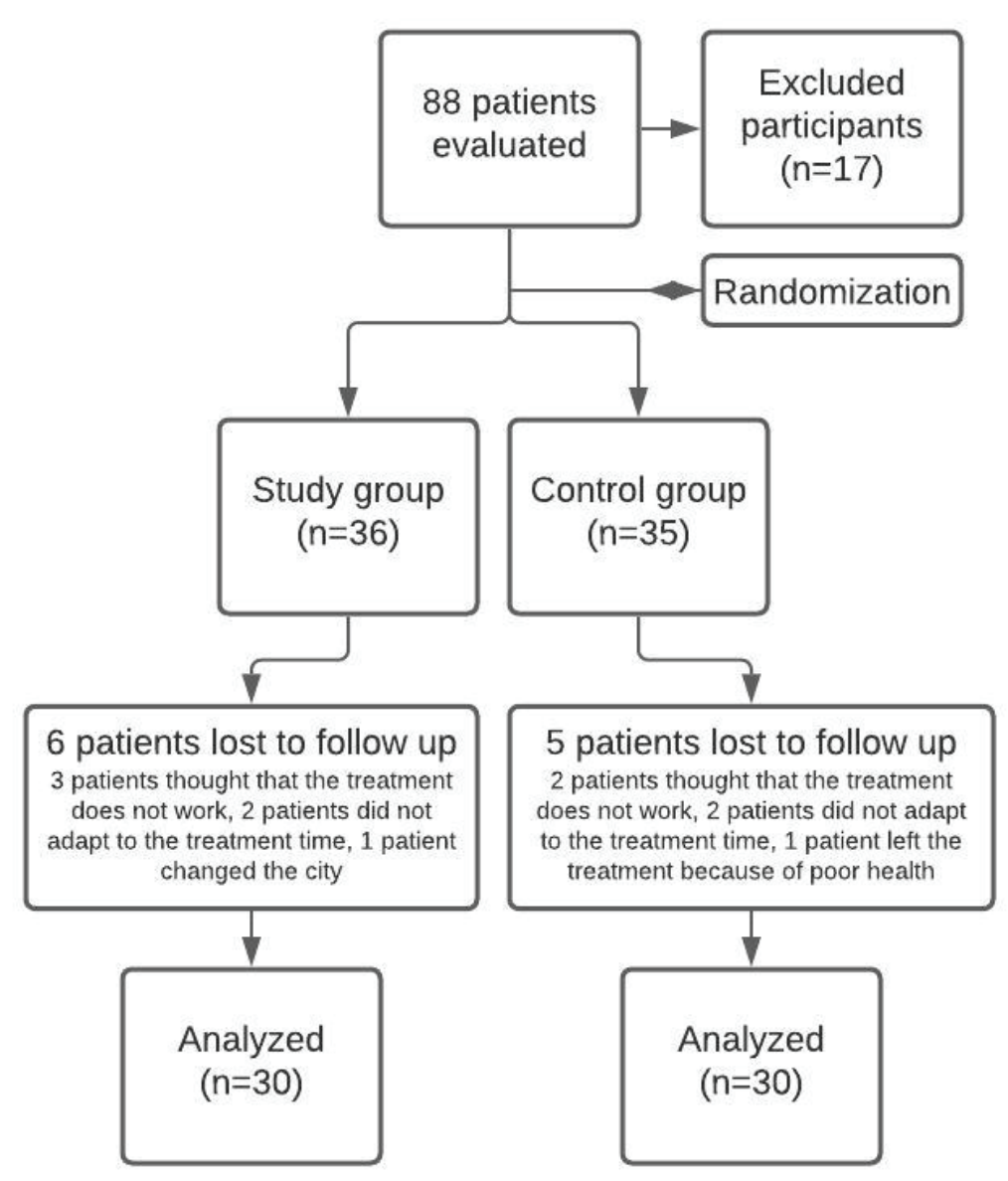

Fig. 1. Flow-chart diagram

(5 days per a week). Twenty minutes of heat application with hotpack, 20 minutes of conventional TENS for pain (Pulse duration: $50 \mu$ s, frequency: $100 \mathrm{~Hz}$ ) and 5 minutes of continuous mode ultrasound for deep heating (at a frequency of $1 \mathrm{MHz}$, and intensity of $1.5 \mathrm{~W} / \mathrm{cm}^{2}$ ) were applied to the cervical region. Exercises were comprised of upper-back strengthening (lower and middle trapezius muscles) and upper extremity stretching exercises, isometric neck exercises for cervical flexors, extensors and rotatores, chin-nod for activation of deep cervical flexors, serratus anterior muscle strengthening that were performed for $5 \mathrm{~s}$ with 10 repetitions (Rest interval: $3 \mathrm{sec}$ ) for both experimental and study groups. Patients performed the exercises 5 days a week during the 3 -week intervention period. A neural mobilization treatment protocol was applied to the study group in addition to conservative physiotherapy for 3 weeks ( 3 days per a week and 4 days in the last week, 10 sessions in total, 10 times for each of three nerves in each sessions). The patients were asked if they had symptoms or not during the nerve mobilization tests. Each neural mobilization was applied for 10 seconds.
Radial nerve mobilization: Elbow extension, shoulder internal rotation, wrist, thumb and fingers flexion and ulnar deviation were performed with the depression of the shoulder girdle while the patient was in the supine position [20] (Fig. 2A).

Median nerve mobilization: Ninety degrees shoulder abduction with shoulder girdle depression, elbow extension, wrist and fingers extension with ulnar deviation were applied while the patient was lying supine position [20] (Fig. 2B).

Ulnar nerve mobilization: Ninety degrees shoulder abduction was performed with shoulder depression while the patient in the supine position, Then, the patient's elbow was brought to $90^{\circ}$ flexion, the hand was brought to the ear while the head was rotated the opposite side, and radial deviation movement was applied with the extension of the wrist [20] (Fig. 2C).

\section{Statistical analysis}

The SPSS Package Program was used for the statistical analyses (SPSS 23.0 for Windows, Chicago, IL, USA). Normality distribution of the data was analyzed. The numerical data were given as arithmetic mean and 


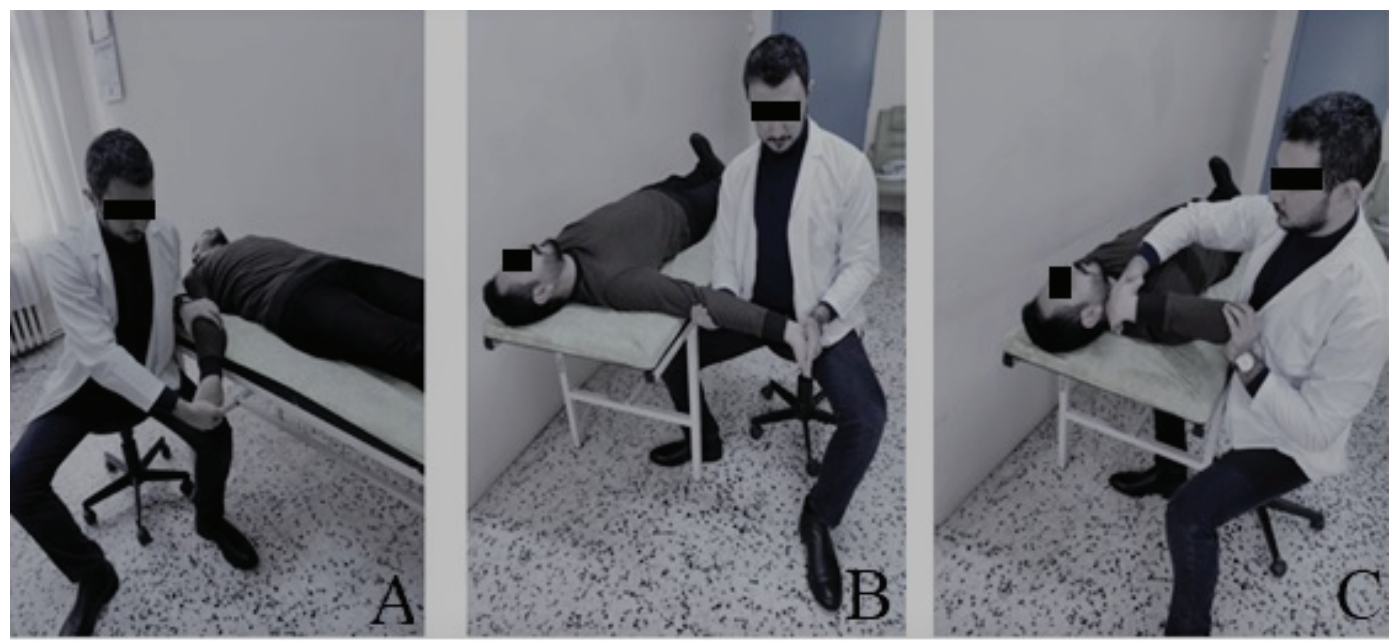

Fig. 2. Application of neural mobilization technique; A: Radial nerve mobilization, B: Median nerve mebolization, C: Ulnar nerve moblization

standard deviations $(\mathrm{X} \pm \mathrm{SD})$. The intra-group comparisons before and after the treatment were analyzed with Paired Sample t-test. In the inter-group comparisons analysis was done by using one way ANOVA test and Bonferroni correction were used to determine the differences amongst the interventions. The statistical significance was set at $\mathrm{p}<0.05$ [21].

\section{Results}

Thirty one $(51.6 \%)$ of the individuals were male, and twenty nine $(48.4 \%)$ were female. Mean age of all participants was $47.23 \pm 12.17$ years. Demographic and anthropometric characteristics of both groups are presented in Tab. 1. There were no significant differences in demographic and anthropometric characteristics between the two groups $(p>0.05)$.

In the study group, it was observed that the tragus-wall and C7-wall distances were significantly decreased after the treatment when compared to the results before the treatment $(p<0.05)$. The distances were similar in the control group before and after the treatment $(p>0.05)$. The groups had similar values before the treatment in terms of the tragus-wall and C7wall distances $(p>0.05)$. After the treatment, there was a significant difference observed between the groups in terms of tragus-wall distances in favor of the study group $(\mathrm{p}<0.05)$. However, there was no difference in terms of C7-wall distance between the groups after the treatment $(\mathrm{p}>0.05)$ (Tab. 2).

In a comparison of the subjective pain values of the groups before and after the treatment, it was observed that the pain values were decreased in resting, sitting and lying positions, and in all neck movements in both groups $(\mathrm{p}<0.05)$. Pre-treatment pain values didn't differ significantly in both groups $(p>0.05)$. After the treatment, it was reported that the pain relief in the study group was more than control group $(p<0.05)$ (Tab. 3$)$.

It was seen that neck mobility in all directions was increased in both groups before and after the treatment $(p<0.05)$. Prior to treatment values in neck extension and right rotation active joint mobility were different between groups $(\mathrm{p}<0.05)$. The other active joint movement ranges didn't differ significantly $(\mathrm{p}>$ $0.05)$. There was no difference between the groups in

Tab. 1. The demographic characteristics of groups

\begin{tabular}{|c|c|c|c|c|}
\hline & $\begin{array}{c}\mathrm{SG}(\mathrm{n}=30) \\
\mathrm{X} \pm \mathrm{SD}\end{array}$ & $\begin{array}{c}\mathrm{CG}(\mathrm{n}=30) \\
\mathrm{X} \pm \mathrm{SD}\end{array}$ & F & $\mathrm{p}$ \\
\hline Age (years) & $47.17 \pm 12.54$ & $47,30 \pm 12.02$ & 0.002 & 0.967 \\
\hline Height $(\mathrm{cm})$ & $165.63 \pm 7.03$ & $166.50 \pm 7.25$ & 0.221 & 0.640 \\
\hline Weight (kg) & $76.73 \pm 8.67$ & $78.90 \pm 8.87$ & 0.916 & 0.343 \\
\hline Body mass index $\left(\mathrm{kg} / \mathrm{m}^{2}\right)$ & $28.10 \pm 4.06$ & $28.61 \pm 4.08$ & 0.236 & 0.629 \\
\hline
\end{tabular}

$\mathrm{p}<0.05$ is statistically significant, One-way ANOVA, SG: Study group, CG: Control group, X: Mean, SD: Standard deviation. 
Tab. 2. The comparison of groups in terms of tragus-wall distance and C7-wall distance before and after the treatment

\begin{tabular}{|c|c|c|c|c|c|c|c|c|}
\hline & \multicolumn{2}{|c|}{ Study group $(\mathrm{n}=30)$} & \multicolumn{2}{|c|}{ Control group $(n=30)$} & \multicolumn{2}{|c|}{$\mathrm{F}$} & \multicolumn{2}{|c|}{$\mathrm{P}_{\mathrm{b}}$} \\
\hline & $\begin{array}{c}\mathrm{BT} \\
\mathrm{X} \pm \mathrm{SD}\end{array}$ & $\begin{array}{c}\mathrm{AT} \\
\mathrm{X} \pm \mathrm{SD}\end{array}$ & $\begin{array}{c}\mathrm{BT} \\
\mathrm{X} \pm \mathrm{SD}\end{array}$ & $\begin{array}{c}\mathrm{AT} \\
\mathrm{X} \pm \mathrm{SD}\end{array}$ & BT & AT & BT & AT \\
\hline $\begin{array}{l}\text { Tragus-wall } \\
\text { distance }\end{array}$ & $\begin{array}{r}13.20 \pm 1.73 \\
P_{a=}\end{array}$ & $\begin{array}{l}11.57 \pm 2.40 \\
.001\end{array}$ & $\begin{array}{r}13.00 \pm 1.51 \\
P_{a}\end{array}$ & $\begin{array}{l}12.60 \pm 1.45 \\
.054\end{array}$ & 0.228 & 4.064 & 0.635 & $0.048 *$ \\
\hline $\begin{array}{l}\text { C7-wall } \\
\text { distance }\end{array}$ & $\begin{array}{r}7.73 \pm 2.02 \\
P_{a}=\end{array}$ & $\begin{array}{l}6.27 \pm 1.20 \\
.001\end{array}$ & $\begin{array}{r}6.87 \pm 1.25 \\
P_{a}\end{array}$ & $\begin{array}{l}6.43 \pm 1.28 \\
.051\end{array}$ & 4.001 & 0.271 & 0.051 & 0.605 \\
\hline
\end{tabular}

$\mathrm{p}<0.05$ is statistically significant, BT: Before treatment, AT: After treatment, X: Mean, SD: Standard deviation, $P_{a}:$ Paired Sample t-test, $P_{b}$ : Results from One-way ANOVA test.

Tab. 3. The comparison of groups in terms of neck pain before and after the treatment

\begin{tabular}{|c|c|c|c|c|c|c|c|c|}
\hline & \multicolumn{2}{|c|}{ Study group $(n=30)$} & \multicolumn{2}{|c|}{ Control group $(n=30)$} & \multicolumn{2}{|c|}{$\mathrm{F}$} & \multicolumn{2}{|c|}{$\mathrm{P}_{\mathrm{b}}$} \\
\hline & $\begin{array}{c}\mathrm{BT} \\
\mathrm{X} \pm \mathrm{SD}\end{array}$ & $\begin{array}{c}\mathrm{AT} \\
\mathrm{X} \pm \mathrm{SD}\end{array}$ & $\begin{array}{c}\mathrm{BT} \\
\mathrm{X} \pm \mathrm{SD}\end{array}$ & $\begin{array}{c}\mathrm{AT} \\
\mathrm{X} \pm \mathrm{SD}\end{array}$ & BT & AT & BT & AT \\
\hline $\mathrm{RP}$ & $\begin{array}{r}4.77 \pm 1.19 \\
P_{a}\end{array}$ & $1.93 \pm 0.98$ & $\begin{array}{r}5.00 \pm 1.23 \\
P_{a}\end{array}$ & $3.07 \pm 1.20$ & 0.555 & 16.025 & 0.475 & $0.000 *$ \\
\hline SP & $\begin{array}{r}4.83 \pm 1.12 \\
P_{a}\end{array}$ & $1.93 \pm 0.94$ & $\begin{array}{r}4.83 \pm 1.23 \\
P_{a}\end{array}$ & $2.97 \pm 1.13$ & 0.001 & 14.785 & 1.000 & $0.001 *$ \\
\hline LP & $\begin{array}{r}3.67 \pm 1.56 \\
P_{a}\end{array}$ & $0.90 \pm 0.84$ & $\begin{array}{r}4.00 \pm 1.36 \\
P_{a}\end{array}$ & $1.93 \pm 0.98$ & 0.775 & 19.128 & 0.382 & $0.001 *$ \\
\hline $\mathrm{F}$ & $\begin{array}{r}4.60 \pm 1.67 \\
P_{a}\end{array}$ & $1.87 \pm 1.14$ & $\begin{array}{r}5.03 \pm 1.40 \\
P_{a}\end{array}$ & $\begin{array}{l}3.27 \pm 1.44 \\
01\end{array}$ & 1.182 & 17.519 & 0.281 & $0.001 *$ \\
\hline E & $\begin{array}{r}5.97 \pm 1.75 \\
P_{a}\end{array}$ & $2.80 \pm 1.19$ & $\begin{array}{r}6.10 \pm 1.47 \\
P_{a}\end{array}$ & $\begin{array}{l}3.83 \pm 1.42 \\
01\end{array}$ & 0.102 & 9.387 & 0.751 & $0.003^{*}$ \\
\hline RLF & $\begin{array}{r}4.80 \pm 1.30 \\
P_{a}\end{array}$ & $2.07 \pm 1.14$ & $\begin{array}{r}5.27 \pm 1.48 \\
P_{a}\end{array}$ & $3.30 \pm 1.32$ & 1.682 & 15.010 & 0.200 & $0.001 *$ \\
\hline LLF & $\begin{array}{r}4.70 \pm 1.39 \\
P_{a}\end{array}$ & $1.77 \pm 1.28$ & $\begin{array}{r}5.30 \pm 1.47 \\
P_{a}\end{array}$ & $3.30 \pm 1.34$ & 2.641 & 20.523 & 0.110 & $0.001 *$ \\
\hline RR & $\begin{array}{r}4.03 \pm 1.47 \\
P_{a}\end{array}$ & $1.43 \pm 1.01$ & $\begin{array}{r}4.43 \pm 1.30 \\
P_{a}\end{array}$ & $2.63 \pm 1.22$ & 1.239 & 17.320 & 0.270 & $0.001 *$ \\
\hline LR & $\begin{array}{r}4.03 \pm 1.27 \\
P_{a}\end{array}$ & $1.30 \pm 1.12$ & $\begin{array}{r}4.37 \pm 1.38 \\
P_{a}\end{array}$ & $2.67 \pm 1.27$ & 0.948 & 19.586 & 0.334 & $0.001 *$ \\
\hline
\end{tabular}

${ }^{*} \mathrm{p}<0.05$ is statistically significant, BT: Before treatment, AT: After treatment, X: Mean, SD: Standard deviation, RP: Resting position, SP: Sitting position, LP: Lying position, F: Flexion, E: Extension, RLF: right lateral flexion, LLF: Left lateral flexion, RR: Right rotation, LR: Left rotation, $P_{a}$ : Paired Sample t-test, $P_{b}$ : Results from One-way ANOVA test. 
Tab. 4. The comparison of groups in terms of joint mobility before and after the treatment

\begin{tabular}{|c|c|c|c|c|c|c|c|c|}
\hline & \multicolumn{2}{|c|}{ Study group $(n=30)$} & \multicolumn{2}{|c|}{ Control group $(\mathrm{n}=30)$} & \multicolumn{2}{|c|}{$\mathrm{F}$} & \multicolumn{2}{|c|}{$\mathrm{P}_{\mathrm{b}}$} \\
\hline & $\begin{array}{c}\mathrm{BT} \\
\mathrm{X} \pm \mathrm{SD}\end{array}$ & $\begin{array}{c}\mathrm{AT} \\
\mathrm{X} \pm \mathrm{SD}\end{array}$ & $\begin{array}{c}\mathrm{BT} \\
\mathrm{X} \pm \mathrm{SD}\end{array}$ & $\begin{array}{c}\mathrm{AT} \\
\mathrm{X} \pm \mathrm{SD}\end{array}$ & BT & AT & BT & AT \\
\hline \multirow[t]{2}{*}{$\mathrm{F}$} & $31.53 \pm 5.42$ & $37.20 \pm 4.86$ & $30.83 \pm 5.80$ & $33.30 \pm 6.29$ & 0.233 & 7.227 & 0.631 & $0.009^{*}$ \\
\hline & \multicolumn{2}{|c|}{$P_{a=0.001}$} & \multicolumn{2}{|c|}{$P_{a=0.001}$} & & & & \\
\hline \multirow{2}{*}{$\mathrm{E}$} & $30.57 \pm 7.79$ & $35.33 \pm 7.05$ & $26.87 \pm 5.49$ & $29.10 \pm 5.62$ & 4517 & 14327 & $0038 *$ & $0001 *$ \\
\hline & \multicolumn{2}{|c|}{$P_{a=0.001}$} & \multicolumn{2}{|c|}{$P_{a=0.001}$} & & & & \\
\hline \multirow{2}{*}{ RLF } & $30.90 \pm 6.76$ & $36.57 \pm 6.11$ & $29.23 \pm 5.39$ & $32.13 \pm 5.32$ & 1114 & 8006 & (0) & $0004 *$ \\
\hline & \multicolumn{2}{|c|}{$P_{a=0.001}$} & \multicolumn{2}{|c|}{$P_{a=0.001}$} & 1.114 & 0.900 & 0.290 & 0.004 \\
\hline \multirow{2}{*}{ LLF } & $32.90 \pm 6.06$ & $38.30 \pm 5.98$ & $30.23 \pm 5.91$ & $32.67 \pm 5.88$ & 1 & 12527 & ( & $0001 *$ \\
\hline & \multicolumn{2}{|c|}{$P_{a=0.001}$} & \multicolumn{2}{|c|}{$P_{a=0.001}$} & 2.914 & 13.521 & 0.090 & 0.001 \\
\hline \multirow{2}{*}{ RR } & $53.87 \pm 9.56$ & $61.60 \pm 9.73$ & $57.37 \pm 8.21$ & $62.33 \pm 8.17$ & 315 & 0035 & 0134 & 0852 \\
\hline & \multicolumn{2}{|c|}{$P_{a=0.001}$} & \multicolumn{2}{|c|}{$P_{a=0.001}$} & 2.010 & & ד. ד. & 0.032 \\
\hline \multirow{2}{*}{ LR } & $54.27 \pm 10.90$ & $62.70 \pm 11.20$ & $59.97 \pm 9.67$ & $63.00 \pm 8.59$ & $501+2$ & & 0026 & ( \\
\hline & \multicolumn{2}{|c|}{$P_{a=0.001}$} & \multicolumn{2}{|c|}{$P_{a=0.001}$} & 4.591 & 0.014 & 0.050 & 0.900 \\
\hline
\end{tabular}

$\mathrm{p}<0.05$ is statistically significant, BT: Before treatment, AT: After treatment, X: Mean, SD: Standard deviation, F: Flexion, E: Extension, RLF: Right lateral flexion, LLF: Left lateral flexion, RR: Right rotation, LR: Left rotation, $P_{a}$ : Paired Sample t-test, $P_{b}:$ Results from One-way ANOVA test.

Tab. 5. The comparison of groups in terms of Neck Disability Index scores before and after the treatment

\begin{tabular}{|c|c|c|c|c|c|c|c|c|}
\hline & \multicolumn{2}{|c|}{$\begin{array}{l}\text { Study group }(\mathrm{n}=30) \\
\mathrm{X} \pm \mathrm{SD}\end{array}$} & \multicolumn{2}{|c|}{$\begin{array}{l}\text { Control group }(\mathrm{n}=30) \\
\mathrm{X} \pm \mathrm{SD}\end{array}$} & \multicolumn{2}{|c|}{ F } & \multicolumn{2}{|c|}{$\mathrm{P}_{\mathrm{b}}$} \\
\hline & $\begin{array}{c}\text { BT } \\
X \pm S D\end{array}$ & $\begin{array}{c}\text { AT } \\
\mathrm{X} \pm \mathrm{SD}\end{array}$ & $\begin{array}{c}\text { BT } \\
X \pm S D\end{array}$ & $\begin{array}{c}\text { AT } \\
X \pm S D\end{array}$ & BT & AT & BT & AT \\
\hline NDI & $\begin{array}{r}18.93 \pm 6.43 \\
P_{a}\end{array}$ & $\begin{array}{l}11.33 \pm 6.10 \\
.001\end{array}$ & $\begin{array}{r}18.93 \pm 5.10 \\
P_{a=}\end{array}$ & $\begin{array}{l}13.37 \pm 5.74 \\
001\end{array}$ & 0.001 & 1.767 & 1.000 & 0.189 \\
\hline
\end{tabular}

$\mathrm{p}<0.05$ is statistically significant, BT: Before treatment, AT: After treatment, X: Mean, SD: Standard deviation, NGGYA: Nottingham Extended Activities of Daily Living scale, NDI: Neck Disability Index, $P_{a}$ : Paired Sample t-test, $P_{b}$ : Results from One-way ANOVA test.

the right and left rotation of active neck movements after the treatment $(p>0.05)$. It was observed that there was a significant difference in the values of other movements of the neck, and the ranges increased more in the study group when compared to the control group $(\mathrm{p}<0.05)$ (Tab. 4).

An improvement was observed in the intra-group comparisons of study and control groups in terms of NDI scores before and after the treatment $(\mathrm{p}<0.05)$. There was no difference in comparisons of both groups $(\mathrm{p}>0.05)($ Tab. 5).

\section{Discussion}

In this study, in which we investigated the effects of a conservative physiotherapy protocol in addition to neural mobilization treatment on cervical posture, pain, and functionality in patients diagnosed with cervical disc herniation, the positive effect of the treatment on cervical posture, reduction in pain and increase in active range of motion was determined.

The prevalence of cervical disc herniation increases with the degeneration in vertebrae especially after the 
age of 40 [22]. Williams et al. stated that neck pain is caused by the degeneration of the discs in individuals of working age [23]. Suzuki et al. evaluated cervical intervertebral discs on the magnetic resonance images of 1059 participants who had neck pain, and they reported that disc degeneration increases with age [24]. In the study conducted by Kim et al., it is argued that cervical disc herniation may result from aging, increased muscle tension and intense work tempo [25]. The average age of the individuals in our study is $47.23 \pm 12.17$, which is similar to the average age of patients with $\mathrm{CDH}$, mentioned in the literature.

Postural changes in the cervical region due to the pathology or that predispose to pathology are natural. In a study, researchers investigated the anterior tilt, and normal range of motion of the neck in patients with cervical disc herniation. In the study, cervical lordosis between $\mathrm{C} 2-\mathrm{C} 7$ was measured, by means of radiological images, to compare the normal range of motion of cervical rotation, flexion and extension in healthy individuals with the same measurements in individuals with cervical disc herniation. It was reported that the patients with cervical disc herniation had significantly reduced neck range of motion, and increased head anterior tilt when compared to the healthy individuals [26]. Sharma et al. stated in their study, that the postural changes in the cervical region are known to negatively affect the mobility and flexibility of the peripheral nervous system, while neural mobilization can relieve tensions in the myofascial muscle chains to gain normal functionality [13]. In our study, we used tragus-wall distance measurement and $\mathrm{C} 7$-wall distance measurement methods to evaluate the cervical posture. After the treatment, the lack of difference in $\mathrm{C} 7$-wall distance measurements in both groups may be related to the occurrence of postural changes with longer-term treatments. However, we believe that the decrease in tragus-wall distance in the study group is due to the decrease in pain, the application of stresses at the muscular level during neural mobilization techniques, and that these stresses may contribute to the flexibility of the muscles in this area.

It has been reported that they reduce the symptoms of edema, and demyelination resulting from root pressure of nerve and dysfunction of microcirculation by restoring homeostasis between the neural tissue and surrounding structures. Studies have shown that neural mobilization reduced intraneural edema, increased intercellular fluid flow, reduced hyperalgesia, and induced the immune response. Also, it has been known that neural mobilization techniques are safer and more target-specific compared to tensioning techniques [27-29].

Beneciuk et al. reported that if a specific stretching technique was performed on the median nerve it had a hypoanalgesic effect on pain. The researchers noted that neural mobilization may be effective in reducing pain by inhibition in the dorsal horn [30]. Savva et al. investigated the effect of neural mobilization on pain, functionality, grip strength, and active joint range of motion in the neck. Forty-two patients were divided into two groups, median nerve mobilization was applied in addition to cervical traction, and the control group was not given any treatment. They noted that neural mobilization plus cervical traction improved pain, functionality, grip strength, and neck normal joint range of motion [31]. In a review article about the effectiveness of neural mobilization in neuromuscular disorders Basson et al. noted that neural mobilization affects lower back, neck and arm pain along with nerve root damage, and it is not effective for carpal tunnel syndrome [15]. Kim et al. observed that the effectiveness of the treatment increased when they applied neural mobilization techniques together with another treatment (manual cervical traction) in patients with cervical radiculopathy. They stated increase in pain, joint range of motion, endurance of the deep flexor muscles, and improvement in the endurance scores of the patients [6]. As can be seen in previous studies, neural mobilization technique contributes to the improvement in parameters such as pain, functionality, active joint range of motion. Also in the studies, neural mobilization in addition to conservative physiotherapy increased the effectiveness of the treatment. In our study, similar to the findings in the literature, healings in pain and active joint range of motion were observed in both groups. All other neck movements, except rotational movements, showed improvement in the study group. We believe that longerterm treatments and manual joint therapy methods may be required to gain more range of motion in rotational movements.

Khan et al. compared the effectiveness of neck mobilization and neural mobilization in patients with cervico-brachial pain. At the end of the treatment, there was significant healing in pain values and NDI score in both groups [32]. Ragonese conducted a study in which he compared manual therapy (cervical lateral glide, neural mobilization, thoracal mobilization) with therapeutic exercises (deep neck flexor, trapezius, and serratus anterior muscle strengthening) in patients with cervical radiculopathy. The pain score of the manual treatment group and the score of the NDI were significantly reduced when compared to the therapeutic exercise group. He stated that neural mobilization, which is applied in addition to therapeutic exercises in patients with cervical radiculopathy, will be more effective on pain [33]. Anwar et al. have investigated the effectiveness of cervical treatment. A conservative treatment protocol consisting of cervical traction, hot pack and 
isometric neck exercises were applied to both groups. Neural mobilization therapy was applied in addition to the individuals in the study group. The functional status of the participants was measured by the NDI. At the end of the study, there was a significant difference in the NDI score in favour of the neural mobilization group [34]. In fact, the findings of studies confirm that the addition of neural mobilization to the conservative treatment provide a significant benefit for functionality in patients with cervical radiculopathy. However, our study only included short-term measurements. We think that long-term follow up may have revealed significant differences.

It can be said that, 3-week routine conservative physiotherapy protocol applied together with 10 sessions neural mobilization in patients with cervical disc herniation has a positive effect on the cervical posture and pain. These treatment protocol improves the active range of motion of the neck. Therefore, this approach may be used as self-practice to complement standard physiotherapy treatment programs for patients with $\mathrm{CDH}$.

\section{Limitations of the study}

Lack of a satisfaction questionnaire for participants that evaluated the applied treatment methods, and the results after the treatment could be recognized as a limitation of our study, and should be considered for future research. There is a gap of a consensus in the literature regarding the frequency and number of repetitions of neural mobilization techniques. In the future studies, we recommend that treatment protocols could be designed by cervical traction, which is most probably would increase the effect of treatment.

\section{Conclusions}

In the light of the findings of our study a significant healing score in the NDI scores was observed in both groups if we consider matters in terms of before and after the treatment, while there was no difference in the NDI scores when the groups were compared with each other. This finding was unlike similar studies in the literature. In conclusion, it can be considered that neither of the treatments are superior to each other in terms of functionality. A decrease in NDI scores in both groups may be due to a decrease in pain after the treatment in both groups. Although it is not possible to homogenize patient groups and symptoms completely, the positive effects of neural mobilization on treatment are clear.

\section{Funding}

This research received no external funding.

\section{Conflict of interest}

The authors declare no conflict of interest.

\section{References}

1. Duymaz T, Yagc1 N. Effectiveness of the mulligan mobilization technique in mechanical neck pain. J Clin Anal Med. 2018; 9(4): 304-9.

2. Onyewu O, Manchikanti L, Falco FJ, Singh V, Geffert S, Helm II, Hirsch JA. An update of the appraisal of the accuracy and utility of cervical discography in chronic neck pain. Pain Physician. 2012; 15(6): 777-806.

3. Karaman S, Uysal M, Yıldırım M, Başol N. Yutma Güçlüğü ve Boğaz Ağrısı ile Gelen Hastada Servikal Disk Protezinin Anterior Dislokasyonu. Gaziosmanpaşa Üniversitesi Tıp Fakültesi Dergisi. 2017; 9(1): 51-7.

4. Cebesoy O, Konukoglu L. Servikal diskojenik ağrılar. Totbid Dergisi. 2017; 16: 304-12.

5. Durmus B. Servikal bölge sorunlarında egzersiz reçeteleme. Türk Fiz Tip Rehab Derg. 2014; 60(2): 15-24.

6. Kim DG, Chung SH, Jung HB. The effects of neural mobilization on cervical radiculopathy patients' pain, disability, ROM, and deep flexor endurance. J Back Musculoskelet Rehabil. 2017; 30(5): 951-59.

7. Savva C, Korakakis V, Efstathiou M, Karagiannis C. Cervical traction combined with neural mobilization for patients with cervical radiculopathy: A randomized controlled trial. J Bodyw Mov Ther. 2021; 26: 279-89.

8. Akhtar M, Karimi H, Gilani SA, Ahmad A, Raza A. The effectiveness of routine physiotherapy with and without neuromobilization on pain and functional disability in patients with shoulder impingement syndrome; a randomized control clinical trial. BMC Musculoskelet Disord. 2020; 21(1): 1-9.

9. Ahmed N, Tufel S, Khan MH, Khan PB. Effectiveness of neural mobilization in the management of sciatica. J Musculoskelet Res. 2013; 16(03): 1350012.

10. Duymaz T. Mobilizasyon Teknikleri Ekstremiteler ve Spinal Teknikler, Hipokrat Kitabevi, 2017.

11. Sambyal S, Kumar S. Comparison between nerve mobilization and conventional physiotherapy in patients with cervical radiculopathy. Int J Innov Res Dev. 2013; 2(8): 442-45.

12. Efstathiou MA, Stefanakis M, Savva C, Giakas G. Effectiveness of neural mobilization in patients with spinal radiculopathy: a critical review. J Bodyw Mov Ther. 2015; 9(2): 205-12.

13. Sharma S, Verma SK, Agarwal V. Effects of neural mobilization in posterior myofascial chain flexibility in normal subjects. Int J Physiother Res. 2015; 3(4): 1122-25. 
14. Aras D, Ahmad H. The Efficacy of Physiotherapy Combination Technique on Pain and Functional Independence of People with Lumbar Disc Herniation. Indian J Public Health Res Dev. 2018: 9(8): 1524-29.

15. Basson A, Olivier B, Ellis R, Coppieters M, Stewart A, Mudzi W. The effectiveness of neural mobilization for neuromusculoskeletal conditions: a systematic review and meta-analysis. J Orthop Sports Phys Ther. 2017; 47(9): 593-615.

16. Shipe NK, Billek-Sawhney B, Canter TA, Meals DJ, Nestler JM, Stumpff JL. The intra-and inter-rater reliability of the tragus wall distance (TWD) measurement in non-pathological participants ages 18-34. Physiother Theory Pract. 2013; 29(4): 328-34.

17. McCaffery M, Pasero C. Practical nondrug approaches to pain. Pain: Clinical manual (2nd Ed.). 1999; p. 399-427.

18. Farooq MN, Bandpei MAM, Ali M, Khan GA. Reliability of the universal goniometer for assessing active cervical range of motion in asymptomatic healthy persons. Pak J Med Sci. 2016; 32(2): 457.

19. Telci EA, Karaduman A, Yakut Y, Aras B, Simsek IE, Yagli N. The cultural adaptation, reliability, and validity of neck disability index in patients with neck pain: a Turkish version study. Spine. 2009; 34(16): 1732-35.

20. Shacklock M. Clinical neurodynamics. 1st ed. Philadelphia: Elsevier Health Sciences. 2005; p. 268-88.

21. Alpar R. Uygulamalı çok degiskenli istatistiksel yöntemler. 344 3rd ed. Ankara: Detay Yayıncılık. 2011; p. 240-50.

22. Adams MA, Lama P, Zehra U, Dolan P. Why do some intervertebral discs degenerate, when others (in the same spine) do not? Clin Anat. 2015; 28(2): 195-204.

23. Williams FMK, Sambrook PN. Neck and back pain and intervertebral disc degeneration: role of occupational factors. Best Prac Res Clin Rheumatol. 2011; 25(1): 69-79.

24. Suzuki A, Daubs MD, Hayashi T, Ruangchainikom M, Xiong $\mathrm{C}$, Phan $\mathrm{K}$ et al. Patterns of cervical disc degeneration: analysis of magnetic resonance imaging of over 1000 symptomatic subjects. Global spine J. 2018; 8(3): 254-59.
25. Kim R, Wiest C, Clark K, Cook C, Horn M. Identifying risk factors for first-episode neck pain: A systematic review. Musculoskelet Sci Pract. 2018; 33: 77-83.

26. Ro H, Gong W, Ma S. Correlations between and absolute rotation angle, anterior weight bearing, range of flexion and extension motion in cervical herniated nucleus pulposus. J Phys Ther Sci. 2010; 22(4): 447-50.

27. Liang L, Feng M, Cui X, Zhou S, Yin X, Wang X, Wei X. The effect of exercise on cervical radiculopathy: A systematic review and meta-analysis. Medicine. 2019 ; 98(45): 1-7.

28. Calvo-Lobo C, Unda-Solano F, López-López D, SanzCorbalán I, Romero-Morales C, Palomo-López P, Rodríguez-Sanz D. Is pharmacologic treatment better than neural mobilization for cervicobrachial pain? A randomized clinical trial. Int J Med Sci. 2018; 15(5): 456.

29. Ayub A, Osama M, Ahmad S. Effects of active versus passive upper extremity neural mobilization combined with mechanical traction and joint mobilization in females with cervical radiculopathy: A randomized controlled trial. J Back Musculoskelet Rehabil. 2019; 32(5): 725-30.

30. Beneciuk JM, Bishop MD, George SZ. Effects of upper extremity neural mobilization on thermal pain sensitivity: a sham-controlled study in asymptomatic participants. J Orthop Sports Phys Ther. 2009; 39(6): 428-38.

31. Savva C, Giakas G, Efstathiou M, Karagiannis C, Mamais I. Effectiveness of neural mobilization with intermittent cervical traction in the management of cervical radiculopathy: A randomized controlled trial. Int $\mathbf{J}$ Osteopath Med. 2016; 21: 19-28

32. Khan MR, Shafi H, Amjad I, Siddiqui FA. Efficacy of Cervical Spine Mobilization Versus Peripheral Nerve Slider Techniques (Neurodynamics) in Cervicobrachial Pain Syndrome. JIIMC. 2015; 10(4): 473-79.

33. Ragonese J. A randomized trial comparing manual physical therapy to therapeutic exercises, to a combination of therapies, for the treatment of cervical radiculopathy. Orthop Phys Ther Pract. 2009; 21(3): 71-6.

34. Anwar S, Malik AN, Amjad I. Effectiveness of neuromobilization in patients with cervical radiculopathy. Rawal Med J. 2015; 40: 34-6. 